\title{
Quality improvement initiatives in neonatal intensive care unit (NICU) for improved care outcomes- a review of evidence
}

\begin{abstract}
Although there has been a considerable reduction in the number of neonatal deaths in NICUs during the last two decades, the management of critically ill infants who are continuously exposed to various risk factors has remained a matter of major concern. Exposure to these stressors has a detrimental effect on the growth and neurodevelopment of critically ill preterm infants. As most of these causes are preventable, it is important to adopt proven quality improvement initiatives in order to improve neonatal care outcomes. The objective of this review is to identify the recent available evidence on the proven quality improvement initiatives in the NICU to improve neonatal health care outcomes.

An extensive literature search was conducted for the English language articles in the EMBASE and MEDLINE databases. A total of 300 articles were retrieved with the keyword search. Further attempts were made to search the reference lists of retrieved articles to identify the relevant studies. The title and abstracts of the retrieved references were screened for relevance, and 29 studies were included in this review.

Some of the proven quality improvement initiatives to improve the neonatal care outcomes in NICU include measures such as maintaining hand hygiene, maintenance and optimization of the central line, improving mother-infant interaction, reducing the risk of bronchopulmonary dysplasia and hypothermia, reducing the exposure of infants to various stressors, and implementing the family-centered care approach.
\end{abstract}

Keywords: Quality improvement, neonatal outcomes, neonatal intensive care unit, preterm infants, quality intervention
Volume 9 Issue | - 2019

\author{
Khaled El-Atawi,' Mahmoud Elhalik,' Swarup \\ Dash $^{3}$ \\ 'Consultant Neonatologist, Pediatric Department, NICU, UAE \\ ${ }^{2}$ Consultant Neonatologist and Head of Pediatric Department. \\ NICU, UAE \\ ${ }^{3}$ Specialist Senior Registrar, Pediatric Department, NICU, UAE
}

\begin{abstract}
Correspondence: Dr. Khaled El-Atawi, Consultant Neonatologist, Neonatal Intensive Care Unit, Pediatric Department, LWCH, Dubai Health Authority, UAE, Email kelatewi@eim.ae
\end{abstract}

Received: August 06, 2018| Published: January 03, 2019

\section{Introduction}

Neonatal morbidity and mortality are recognized as a global public health challenge in developing countries, with the highest rate of mortality found in the poorest countries. ${ }^{1}$ The first four weeks of an infant's life is their most vulnerable period, during which they are prone to significant morbidity and mortality. The NICU did not exist until the early 1960s, and the specialty of neonatology did not begin until the 1970s. These special units were established soon after the death of President John F. Kennedy's newborn son, who died of respiratory distress and immature lungs. He was born prematurely after just thirty-four weeks of gestation. His death brought increased awareness in the United States to the numbers of preterm infants who were dying because of immature lung development shortly after their births. Knowledge and expert care of these infants increased, and by the early 1990s, more than 90 percent of these premature infants were surviving, including those infants born as early after just twenty-four weeks of gestation. Exposure of neonates to infections, birth asphyxia, and birth before term are considered as the most common causes of neonatal deaths. However, these common causes of the neonatal mortality in the neonatal intensive care units are mostly preventable. ${ }^{2}$

Although there has been a considerable reduction in the number of neonatal deaths in the NICU during the last two decades, it is the management of critically ill infants that has become of major concern, as they are continuously exposed to various risk factors. ${ }^{3}$ These factors include exposure to various stressors in NICU such as light and noises, exposure to severe infections, high risk of accidental extubations, and invasive procedures. All these factors have a detrimental effect on the growth and neurodevelopment of the critically ill preterm infants. As most of these causes are preventable, it is important to adopt various proven quality improvement initiatives to improve neonatal care outcomes.

This review mainly focuses on the identification of preventable causes of negative neonatal outcomes in the NICUs, and reviews the currently available evidence on the interventions implemented to prevent these causes.

\section{Methods}

An extensive literature search was conducted for the English language articles in the EMBASE and MEDLINE databases. A total of 300 articles were retrieved with the keyword search. Further attempts were made to search the reference lists of retrieved articles to identify the relevant studies. An internet database search was made to include all articles. The keywords used to retrieve this data were 'quality improvement', 'quality initiatives', 'neonatal outcomes', 'health outcomes', 'care outcomes', 'neonatal intensive care unit', 'NICU', 'preterm infants', 'preterm neonates', 'low birth weight infants', 'low birth weight neonates', 'quality team', 'quality intervention', 'premature infants', 'premature neonates'. 


\section{Characteristics of included studies are:}

The studies included in this review were published between 1984 and 2017. All of these studies discussed at least one quality improvement intervention in the NICU to improve the neonatal care outcomes. Descriptive statistics were used in most of these studies.

\section{Results}

A total of 29 studies are included in this review. High rates of neonatal morbidity and mortality in the neonatal intensive care unit are caused by many stressors, most of which are preventable. Figure 1 depicts the clinical processes that are modifiable, and which had a substantial impact on the primary drivers of poor health outcomes.

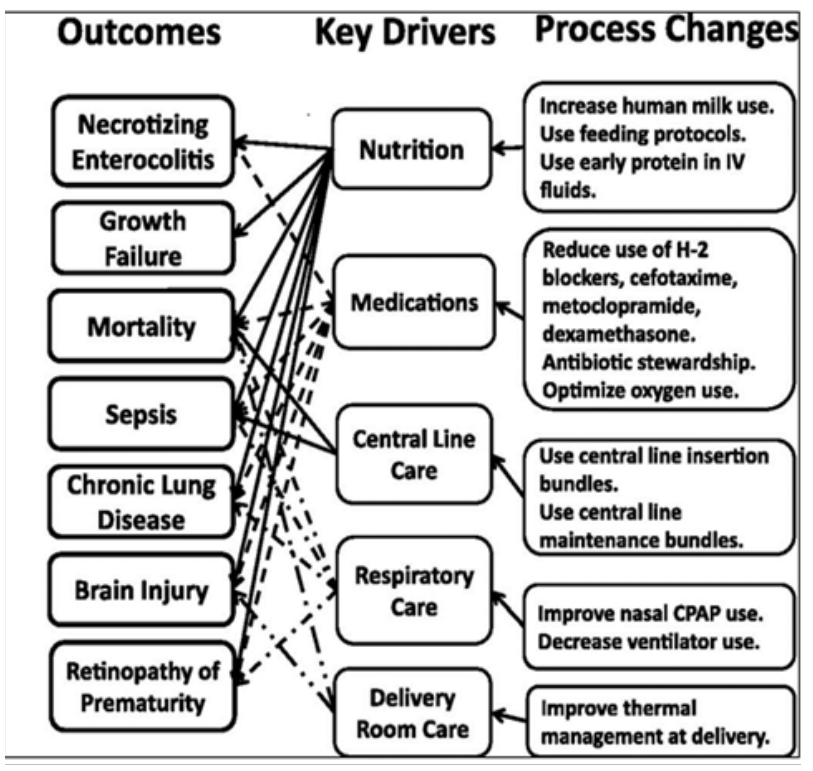

Figure 1 Depiction of outcomes and key drivers of process change in NICU Adapted from "A multifaceted approach to improving outcomes in the NICU: the pediatrix100 000 babies campaign" 66

The quality improvement interventions which improve the neonatal care outcomes are discussed below:

\section{Pain Assessment}

Pain management may be one of the most unrecognized elements of neonatal care. Exposing the preterm infants to various invasive and surgical procedures in the NICU may result in poor neurological development, increased sensitivity, and even death. Hence, proper pain assessment, documentation, and management are required in an NICU to prevent adverse outcomes due to pain in infants. Pain may be difficult to assess in infants when compared to adults, as pain is a subjective feeling. Various physiological, hormonal and metabolic changes have been observed in infants while undergoing painful therapeutic procedures. These observed changes include fluctuation in heart rate, an increase in cortisol levels in the infant's plasma, an increase in epinephrine and norepinephrine levels, increased sweating in the palms, and changes in oxygenation, which may be indicative of pain in infants. ${ }^{4}$

One of the surveys conducted in 2003 in several Italian NICUs found inadequate management of procedural pain. A national pain guideline was formulated and implemented in 2005 in all NICUs. A follow-up survey after 5 years revealed the following results: There was an improvement in the use of analgesia and sedation for invasive procedures, but adherence to best practices for pain control and monitoring was not performed routinely or in an optimal manner. This study found that, despite tremendous efforts, analgesia is not consistently reaching the bedside of patients. Thus, NICU staff should pay closer attention to the aforementioned symptoms when exposing neonates to painful procedures, and should take appropriate steps for the management of pain.

Ozawa et al. ${ }^{6}$ conducted a prospective pre-/postintervention study to improve neonatal pain management for invasive bedside procedures in seven level-III NICUs in Japan from September 2014 to January 2016. They found a substantial improvement in pain management during the 12-month intervention period. Reavey et al. ${ }^{7}$ conducted a study in a tertiary care NICU in order to improve their pain assessment and documentation using a neonatal pain tool, the Neonatal Pain, Agitation, and Sedation Scale. There was a marked improvement in pain assessment and documentation after two years of using this intervention (N-PASS).

After the assessment of pain, the next step is the adequate management of neonates experiencing pain. The NICU staff should focus on pain management methods such as reducing the number of painful procedures, treating postoperative pain immediately after a surgical procedure, preventing prolonged and repetitive invasive procedures, and treating the acute pain with medications which have been proven to be safe for infants.

\section{Reduction of Central Line Associated Blood Stream Infections (CLABSI)}

Central venous catheters have long been a cornerstone of the treatment of critically ill neonates in the NICU. However, these are prone to infections which can cause significant morbidity and mortality in neonates. ${ }^{8}$ These infections were found to be associated with adverse outcomes on growth and neurodevelopment in the neonates. Ting et al. ${ }^{9}$ had used the following 10 step regimen for the reduction of central-line associated bloodstream infections (CLABSI):

i. Observing the existing practices

ii. Conducting an awareness intervention for NICU staff

iii. Establishing a skin preparation protocol to avoid skin injury in neonates

iv. Cleaning of IV ports, tubes, and ampoules

v. Proper central-line insertion

vi. Maintaining sterile towels, gowns, and caps in the central-line insertion premises

vii. Availability of sterile surgical masks

viii. Use of disposable surgical blades

ix. Maintenance of central venous lines regularly

x. Following proper hand hygiene

Following this 10-step regimen resulted in a considerable reduction in the rate of these infections from 7.9 to 2.2 per 1000 catheter days through the study period. The antiseptic for skin used in this study was chlorhexidine gluconate in alcohol, which reduced the rate of central line-associated infections. The policies adopted by Ting et al. ${ }^{9}$ for neonatal skin protection included wiping away excess antiseptic with normal saline immediately after disinfection and avoiding iodinebased products for skin disinfection.

Several other studies reported similar findings as a significant reduction in the rate of infections associated with the central venous catheters (Table 1). 
Table 1 Studies reporting outcomes of quality improvement initiatives for reduction of CLABSI

\begin{tabular}{|c|c|c|c|c|c|}
\hline $\begin{array}{l}\text { SI. } \\
\text { No }\end{array}$ & Study & Quality improvement initiative & $\begin{array}{l}\text { Rate of } \\
\text { CLABSI (pre } \\
\text { intervention) }\end{array}$ & $\begin{array}{l}\text { Rate of } \\
\text { CLABSI (post } \\
\text { intervention) }\end{array}$ & Conclusion of the study \\
\hline I & Bowen et al." & $\begin{array}{l}\text { Implementation of potentially better } \\
\text { practices to reduce infection and } \\
\text { providing awareness to NICU staff }\end{array}$ & $9.9 \pm 4.3$ & $5.4 \pm 1.7$ & $\begin{array}{l}\text { More than } 50 \% \text { reduction in the } \\
\text { infections in premature infants in the } \\
\text { NICU }(p=0.012)\end{array}$ \\
\hline 2 & $\begin{array}{l}\text { Bizzarro et } \\
\text { al. }^{17}\end{array}$ & $\begin{array}{l}\text { Educational intervention to provide } \\
\text { guidelines for placement and management } \\
\text { of central venous catheters to NICU staff }\end{array}$ & 8.4 & 1.28 & $\begin{array}{l}\text { Significant reduction in CLABSI rate as } \\
\text { well as overall sepsis rate }\end{array}$ \\
\hline 3 & $\begin{array}{l}\text { Koeppel et } \\
\text { al. }^{12}\end{array}$ & $\begin{array}{l}\text { Best practices involving decrease central } \\
\text { line entry with the help of closed } \\
\text { medication system }\end{array}$ & 8.25 & 0.65 & $\begin{array}{l}\text { CLABSI rate reduced by } 92 \% \text { over a } \\
\text { period of } 10 \text { years in the intervention } \\
\text { phase }(p=<0.00 I)\end{array}$ \\
\hline 4 & Zhou et al. ${ }^{14}$ & $\begin{array}{l}\text { A multifaceted infection control program } \\
\text { was introduced }\end{array}$ & 16.7 & 5.2 & $\begin{array}{l}\text { There was a steady and sustainable } \\
\text { decrease in the CLABSI rate } \\
\text { throughout the } 3 \text { phases }\end{array}$ \\
\hline 5 & Byrd et al. ${ }^{15}$ & $\begin{array}{l}\text { - barrier precautions for central line } \\
\text { insertion }\end{array}$ & 8.8 & 2 & $\begin{array}{l}\text { CLABSI rate reduced by } 77 \% \\
\text { throughout the intervention period }\end{array}$ \\
\hline
\end{tabular}

sterility of catheters and tubes

regular documentation and monitoring of central lines by NICU staff

hygiene maintenance

Davis et al., ${ }^{10}$ reported a significant correlation between sepsis prevention and positive neurodevelopmental outcomes. Cognitive disability and cerebral palsy were found to be significantly reduced in very low-birthweight infants after implementation of a sepsis quality improvement program in the NICU.

\section{Prevention of Sepsis}

Sepsis is considered to be one of the most common causes of neonatal morbidity and mortality in preterm infants in NICUs, accounting for one-third of all neonatal deaths.

Bowden et al. ${ }^{11}$ in 2011 demonstrate a $>50 \%$ reduction in BSI in extremely premature neonates from D3 to 35 following a collaborative quality improvement project to reduce neonatal infection across a NICU network consisting of eight neonatal intensive care units (NICUs) in New South Wales, Australia. Koeppel et al., ${ }^{12}$ on a 10year review of CLABSI prevention efforts in NICUs, demonstrated that the implementation of QI processes that include strict compliance to best practices and decreasing central line entry by use of a closedmedication system were associated with a significant and sustainable reduction in CLABSI rates.

Following this intervention has significantly reduced the sepsis rate $(5.19 \%$ to $2.46 \%)$ in this NICU. Kaplan et al. ${ }^{13}$ conducted an interrupted time series study in 24 Ohio NICUs. The study aimed to reduce the frequency of late-onset bacterial infections in infants born during 22 to 29 weeks' gestation. They used collaborative quality improvement methods to implement evidence-based catheter care. They found a $20 \%$ reduction in the length of stay (LOS) after implementation of the quality improvement (QI) project over a period of one year. ${ }^{13}$

Zhou et al. ${ }^{14}$ conducted a prospective before and after intervention study follow-up among patients with central lines at the NICU, with a 1-year follow up. The study was conducted in 3 phases: before, during, and after the intervention. They found a significant reduction in overall CLABSI rate from 16.7 per 1,000 central line (CL) days in phase 1 to 7.6 per $1,000 \mathrm{CL}$ days in phase $2(\mathrm{P}=.08)$ to 5.2 per 1,000 CL days in phase 3 . Byrd et al. ${ }^{15}$ demonstrated that better CLABSI reduction could be achieved by forming a team of both doctors and nurses. Harris et al. ${ }^{16}$ showed that by assigning nurses instead of phlebotomists for the collection of blood for culture, it was possible to reduce the rate of contamination by $53 \%$ from $5.19 \%$ to $2.46 \%$ in a one year period. Bizzarro et al. ${ }^{17}$ showed that by doing educational intervention designed to improve the quality of NICU practices and adhering to evidence-based guidelines, it is possible to significantly reduce the rate of CLABSI and therefore of late-onset sepsis.

Topical emollients are commonly used for the prevention of skin injury in neonates in NICUs. However, they increase the risk of nosocomial infections, especially staphylococcal infections. Hence, these should not be given to critically ill premature infants. Probiotics can be used to prevent necrotizing enterocolitis, as they contain anaerobic bacteria. Fluconazole helps in the decolonization of invasive candidiasis in very low-birthweight infants. A meta-analysis of randomized controlled trials of orally administered lactoferrin for prevention of sepsis and necrotizing enterocolitis suggested a decrease in the development of late-onset sepsis (RR $0.49,95 \%$ CI $0.32-0.73$ ) and all-cause mortality (RR $0.30,95 \%$ CI $0.12-0.75$ ). ${ }^{19}$

\section{Prevention of Necrotising Enterocolitis (NEC)}

Necrotizing enterocolitis (NEC) is the leading cause of gastrointestinal emergency in preterm neonates, and contributed significantly to neonatal morbidity and mortality. ${ }^{20}$ The incidence of NEC in infants with birth weight less than 1500 gms has remained constant over the years $(5 \%$ to $7 \%))^{20,21}$ There was a slight increase in NEC related morbidity and mortality rate reported in a study. ${ }^{21}$ The incidence of NEC increased steadily, from 3\% in infants weighing between $1250 \mathrm{gms}$ and $1500 \mathrm{gms}$ to $12 \%$ in infants weighing between $500 \mathrm{gms}$ and $750 \mathrm{gms}$. The mortality rate in those two groups was found to be $16 \%$ and $42 \%$, respectively. ${ }^{22,23}$ Infants who survived with NEC were at an increased risk of poor neurodevelopmental outcomes. ${ }^{22,23}$ 
Despite decades of dedicated research, the pathogenesis of NEC remained poorly understood. The current understanding of the origin of NEC is multifactorial. The proposed mechanism includes a combination of impaired intestinal perfusion, abnormal bacterial colonization, and disturbed gut barrier function. An immature, overactive immune response leading to intestinal inflammation, ischemia, and eventual necrosis also contribute in NEC etiology. ${ }^{24}$ Diagnosis of this multi-factorial disease remained primarily dependent on clinical features that vary significantly due to the multiple predisposing conditions. This heterogeneity makes the development of quality improvement strategies for the prevention of NEC challenging.

Proposed quality improvement practices for prevention of NEC include delayed cord clamping and cord milking, standardized enteral feeding guideline, exclusive feeding of own mother's milk (OMM) and use of donor human milk if OMM not available, feeding guidelines during packed $\mathrm{RBC}$ transfusion, and use of probiotics.

A Cochrane review performed by Rabe et al. ${ }^{25}$ in the year 2012 included 15 studies of 738 infants ( 24 to 36 weeks gestational age), with delayed cord clamping (30-120seconds). The review demonstrated a lower risk of NEC ( 5 trials; 241 infants; RR 0.62, CI, 0.43-0.90) with less risk associated with greater placental transfusion. In a systematic review conducted by Garg et al. ${ }^{26}$ in the year 2017 included six randomized control trials (RCTs). There was a statistically significant decline in the incidence of NEC in the DCC group (12.2\% vs $20.6 \%$; risk ratio (RR) $0.59 ; 95 \%$ CI $0.37-0.94 ; \mathrm{p}=0.02$; number needed to treat $(\mathrm{NNT})=12) .{ }^{23}$ However, given the small sample sizes and other limitations of these studies, the author concluded that current evidence is not sufficient.

Patel et al., ${ }^{27}$ in a QI initiative described cord milking among 158 infants (median GA 27.4 [23.1,29.9], median BW $960 \mathrm{~g}[410,1010])$ compared with 160 historical controls (median GA 27.1 [23,29.9], median BW $880 \mathrm{~g}[375,2050])$. This study revealed a significant decrease in NEC from $20 \%$ to $11 \%(\mathrm{P}<.05)$. Despite available evidence, the benefit of delayed cord clamping and cord milking needs further investigation.

Talaveraet al., ${ }^{28}$ conducted a quality improvement initiative in 2011. Elements included standardized early human milk feedings, conservative feeding guidelines during blood transfusions, indomethacin treatment, and restriction of ranitidine use in VLBW infants. They found a significant reduction in NEC from $8 \%$ to $3.1 \%$ after the implementation of this QI strategy. They concluded that early human milk feedings and conservative feeding during blood transfusion policies appear to have a significant impact on the reduction of NEC

Numerous randomized controlled trials had demonstrated a decreased incidence of NEC when premature infants were fed exclusively with human milk, compared with the formula-fed infants. There is another evidence of decreased incidence of NEC in premature infants fed exclusively with donor breast milk when compared with formula feeding. Recent Cochrane reviews had concluded that all premature infants should be fed with human milk when available.

Patel et al. demonstrated a significant reduction in NEC incidences from $19.4 \%$ to $2.9 \%$ in VLBW infants after initiation of the quality improvement project. ${ }^{27}$ Similar reduction in the rate of NEC incidences were observed by Alshaikhet al., ${ }^{29}$ (odds ratio $=0.32 ; 95 \%$ confidence interval, 0.11-0.93) after a QI initiative.

The efficacy of probiotics to reduce NEC was being investigated by multiple RCTs and cohort studies. A systematic review and meta- analysis performed by Aceti et al. ${ }^{30}$ reported reduced NEC in preterm infants post-probiotics treatment. Probiotics prevented NEC in preterm infants (RR 0.47 [95\% CI $0.36-0.60], \mathrm{p}<0.00001$ ) and in very low-birthweight infants (RR 0.48 [95\% CI 0.37-0.62], $\mathrm{p}<0.00001$ ) ${ }^{30}$

There were insufficient data for extremely low-birthweight infants. A recent Cochrane review concluded that probiotic supplementation in premature infants was associated with a decrease in both overall mortality and incidence of NEC. The review showed that supplementation of enteral probiotics significantly reduced the incidence of severe NEC (stage II or more) (typical relative risk (RR) $0.43,95 \%$ confidence interval (CI) 0.33 to 0.56 ; 20 studies, 5529 infants) and mortality (typical RR $0.65,95 \%$ CI 0.52 to 0.81 ; 17 studies, 5112 infants). Even though there is sufficient evidence in favor of the use of probiotics, a number of questions still remain regarding the selection of the correct strain, dose, duration and safety of probiotics in preterm neonates. ${ }^{31}$

\section{Hand hygiene}

Hand hygiene plays an important role in preventing nosocomial infection in NICUs. ${ }^{32}$ Infections are easily transmitted during the dayto-day caring process in the NICU. Some of the factors which are responsible for infections and which can be curbed by maintaining hand hygiene are listed below: ${ }^{33}$
i. Inserting a central venous catheter
ii. Blood sample collection
iii. Treating and dressing of wounds
iv. Changing parenteral fluid
v. Infusing drugs through intravenous route
vi. Maintaining a central line
vii. Suctioning through the endotracheal tube
viii. Prolonged contact with the infant while providing care like bathing, changing position, physiotherapy
ix. Daily vitals recording
x. Administering drugs through the oral route
xi. Tube feeding
xii. Skin contact while changing diapers

Barbosa et al. ${ }^{34}$ have demonstrated that compliance to hand hygiene guidelines was poor in the selected NICU. An alcohol-based hand rub was found to reduce the nosocomial infections significantly. The rate of nosocomial infections before the intervention was 21.5 per 1000 days, which drastically reduced to 3.2 by the end of the intervention period. Antibiotics usage reduced as a result of the decreased infection rate. ${ }^{35}$ Meta-analysis using a random effects model indicated that a range of strategies, such as educational campaigns, musical parodies, reminders, easy access to hand hygiene sanitizers, UV sensors and performance feedback, improved HHC [odds ratio (OR)2.04; 95\% confidence interval (CI) 1.40, 2.97]. Studies which specifically provided performance feedback at either the individual or group levels reported a more significant improvement in HHC compared to those who did not participate in the study (OR 2.81; 95\% CI 1.32, 5.96 vs. OR $1.55 ; 95 \%$ CI $1.13-2.11) .{ }^{36}$

\section{Mother-infant interaction}

Several studies have highlighted the effects of mother-infant interaction on neurodevelopmental outcomes in the preterm infants. ${ }^{37,38}$ Preterm infants in the NICU are highly susceptible to behavioral, motor, mental and language developmental delays. Hence, a positive 
interaction of the infant with the mother and family is required to improve the neurodevelopmental outcomes.

Chorna et al. ${ }^{39}$ have shown that use of a pacifier-activated music player with a recording of the mother's voice drastically improved the oral feeding skills in preterm infants. Nervous system maturation is required to coordinate the oropharyngeal muscles for oral feeding. Hence, there is an improvement in the neurodevelopmental outcome with this quality improvement initiative in the preterm infants.

Reynolds et al., ${ }^{40}$ have observed a statistically significant correlation between parental holding and presence with neurobehavioral outcomes. The positive effects seen in the neonates were better movements, reduction in stress, arousal, and excitability.

A recent randomized clinical trial conducted at a NICU of an urban medical center supported the findings of Chorna et al. ${ }^{39}$ and Reynolds et al. ${ }^{40}$ In this study, the selected cohort was infants prone to developmental disabilities. The interaction between mother and infant resulted in an improvement of oral feeding and better weight gain. Hence, it is recommended that nurses and other NICU staff monitor and encourage mother-infant interaction, such as holding, presence, and skin to skin contact with parents. Once the preterm infant becomes alert, mothers must be encouraged to interact with them in different positions and should provide positive feeding. ${ }^{41}$

\section{Breast milk nutrition}

Premature infants have different nutritional needs than mature term infants, for whom human milk provides the required nutrition. Preterm infants require fortified human milk in order to meet their growth and neurodevelopmental needs. The nutrition in mother's milk helps in reducing the risk of necrotizing enterocolitis and sepsis, and enhances the growth and neurodevelopment of the premature infant. Infants fed with mother's milk are also less prone to develop metabolic syndrome, low BP, or fewer LDL levels in the later stages of their life. ${ }^{42}$

Luton et al. ${ }^{43}$ have demonstrated a $83 \%$ reduction in the errors associated with feeding the preterm infants in NICU through a proven quality improvement initiative. The expression of human milk and its storage and fortification in this NICU was carefully monitored by the quality improvement team to avoid feeding errors. This intervention ensures that the infants are provided required nutrition, which enhances their growth and neurodevelopment. Meier et al. ${ }^{44}$ also demonstrated similar results.

Oza-Frank et $\mathrm{al}^{45}$ have tested the effectiveness of a quality improvement initiative to reduce human milk errors in a large NICU over a period of 6 years. During this period, they noted errors regarding human milk. The most common errors were switching of milk among the infants, administration of expired milk, and errors in the preparation and fortification of milk. There was a significant decline in the number of errors after the intervention (Table 2).

A recent study reported favorable outcomes with the breastfeeding quality improvement initiative in extremely low-birthweight infants. These outcomes were an improvement in the breastfeeding rate, which in turn reduced the duration of parenteral feeding and intolerance to nutrition. ${ }^{46}$ These results were similar to two previous studies which provided evidence to support the use of nutrition from human milk or breastfeeding over infant formula. Positive outcomes were seen with breastfeeding, which largely included a reduction in risk of necrotizing enterocolitis, and enhancement of growth. ${ }^{47}$ Cristifal et al. ${ }^{48}$ shows that in extremely preterm infants, use of human milk in place of preterm formula significantly reduces the rate of NEC (3 vs $21 \%$ ) and decreased need for parenteral nutrition ( 27 vs 36 days). ${ }^{48}$

Table 2 Reduction in human milk errors

\begin{tabular}{llll} 
SI. No. & Type of error & $\begin{array}{l}\text { Pre intervention } \\
\text { (Number of } \\
\text { errors per 1000 } \\
\text { bottles) }\end{array}$ & $\begin{array}{l}\text { Post intervention } \\
\text { (Number of errors } \\
\text { per 1000 bottles) }\end{array}$ \\
\hline I & Expired milk & 84 & 8.9 \\
2 & $\begin{array}{l}\text { Preparation error } \\
\text { Wrong-milk-to- }\end{array}$ & 4.8 & 2.2 \\
3 & $\begin{array}{l}\text { Wrong-mant } \\
\text { wrong-infant }\end{array}$ & 8.3 & 2 \\
\hline
\end{tabular}

\section{Stress reduction}

Structure and function of the brain in preterm infants admitted to NICU was shown to be altered by their exposure to stress. The changes seen in the infants exposed to stress included a reduction in the size of the brain, reduction in functional ability, and abnormality in motor behavior. Some of the most common stressors experienced in NICU included changing of diaper, intubation, exposure to light and noises, and invasive procedures or interventions. ${ }^{49}$

Floyd highlighted some recommendations for the infant stress reduction quality improvement team which included the following: ${ }^{50}$

i. Maintaining an infant friendly environment the in NICU, including reduction of light and noises

ii. Care for neonatal development (improving mother-infant interaction, maintaining skin to skin care, improving social interaction)

iii. Improving suctioning techniques (suctioning should be done only when the infant is symptomatic, maintaining the position of head of the infant to the midline)

iv. Improvising the admission process in NICU

Vignochi et al. ${ }^{51}$ demonstrated the effects of aquatic physical therapy on agitation and sleep cycle of clinically stable infants in NICU. This therapy involves placing neonates in a liquid medium for about 10 minutes, with movements produced to stimulate their body posture and organization. This intervention improved the sleep cycle and reduced pain, crying, and agitated movements in the infant.

A recent meta-analysis summarized the benefits of music therapy in promoting neurological maturation and oxygen saturation, and shortening the length of stay of preterm infants in the NICU. This music therapy was proven to reduce stress in preterm infants and promote independent breastfeeding. Thereby, the length of stay and the costs of hospitalization for preterm infants reduced significantly after the intervention. ${ }^{52}$

\section{Prevention of unplanned extubation}

Premature infants need mechanical ventilation more often than their term mature counterparts. Ventilation is provided through the endotracheal tube. Mechanically ventilated neonates are prone to adverse events such as unplanned extubations. These are one of the most common adverse events in NICUs, leading to devastating and serious cardiac and respiratory outcomes. Unplanned extubations can be either deliberate (removal by the infant) or accidental (by NICU 
staff during the provision of medical care). ${ }^{53}$ The positive part is that these unplanned extubations are preventable adverse events.

Veldman et al..$^{53}$ found that the most common reason for unplanned endotracheal tube extubation (UEE) was poor and difficult fixations of the end tracheal tube, followed by the active and agitated infant with vigorous movements of the patient in the incubator or bed. They also found that the majority of infants (75\%) did not need reintubation. Among the UEE infants, $41 \%$ managed with nasal CPAP and 33\% did not require any respiratory support. Reintubation was needed only in $25 \%$ of infants.

Creeze K L et al. ${ }^{54}$ demonstrated a $64 \%$ decrease in total UEE events in a NICU (from $46 \%$ to $21 \%)(\mathrm{P}<.001$ ) during a 1year period after implementation of standardized guideline to prevent UEE and Quality improvement initiative.

These studies reported awareness and education of NICU staff as the main quality improvement initiative to prevent this devastating adverse event.

\section{Management of bronchopulmonary dysplasia}

Bronchopulmonary dysplasia is a form of lung injury where there is an arrest of alveolar development. The known preventable causes of BPD are antenatal exposure to infections, intubation, and oxygen therapy. Several studies had previously reported on pharmacological interventions to treat this condition, like bovine superoxide dismutase, corticosteroids during seven to 14 days of life, vitamin A, and caffeine. $^{55}$

Guimarães et al. ${ }^{56}$ have observed and compared the clinical practices to reduce BPD risk in premature infants in five NICUs. Based on their observations, the preventive strategies recommended are: use of prenatal corticosteroids, use of lower $\mathrm{FiO}_{2}$, careful administration of fluids in the early weeks of life, and prevention of sepsis and patent ductus arteriosus. Hence, these quality improvement interventions can be adhered to in NICUs to prevent bronchopulmonary dysplasia and its associated morbidity. In addition to this, several specific strategies have shown evidence of reducing Chronic Lung Disease (CLD). These include early continuous positive airway pressure (CPAP), selective Surfactant, caffeine, gentle ventilation, and extubation guideline. ${ }^{57}$

In the Vermont-Oxford Breathsavers group, 19 hospitals participated in the adoption of potentially best practices (PBPs) during a 2-year collaborative QI project. It consisted of 3600 very low birth weight (VLBW) infants during the collaborative time periods. In fifteen out of nineteen hospitals, a decreasing rate of CLD was observed during this project, and the pooled data across the collaborative demonstrated a statistically significant reduction in CLD rates. A statistically significant increase in survival of VLBW infants without CLD was observed. ${ }^{58}$

A center implemented five PBPs in infants born before 33 weeks of gestation, with noninvasive ventilation (bubble CPAP), and strict intubation and extubation criteria. The study demonstrated a reduction in CLD rates from $17 \%$ pre-intervention to $8 \%$ postintervention. ${ }^{59}$

\section{Prevention and management of hypothermia}

Due to the high surface area to volume ratio, the infants are at a high risk of rapid heat loss, which leads to hypothermia. It is even more of a concern in the very low birth weight infants admitted to NICU. Prolonged heat loss results in an increased expenditure of calories in producing heat, rather than enhancing growth and development.
Godfrey et al. ${ }^{60}$ introduced a quality improvement initiative for the management of hypothermia in very low-birthweight infants in an NICU. All the premature infants were placed in a bag immediately after birth from the neck down. These occlusive bags prevented the hypothermia.

Evidence indicated that preterm (less than 37 weeks) and low birth weight (less than $1.5 \mathrm{~kg}$ ) infants are more prone to hypothermia during the perioperative period than their mature and normal weight counterparts. Hypothermia has shown to be a declining trend from $23 \%$ to $6 \%$ after the introduction of quality improvement interventions like transport protocol and maintenance and continuous monitoring of the rectal temperatures.

Harer et al., ${ }^{61}$ implemented a multidisciplinary guideline for delivery room thermoregulation management for infants born before 35 weeks. Clinical practice changes in the guideline included: increased operating room temperatures, obtaining of a 10-min axillary temperature, use of an exothermic mattress for all infants born before 35 weeks, and use of a polyethylene wrap for infants born before 32 weeks of gestation. They found a significant reduction in the incidence of hypothermia $\left(<36.5^{\circ} \mathrm{C}\right.$ ) (decreased from $63 \%$ to $30 \%$, $\mathrm{P}<0.001)$ and moderate hypothermia $\left(<36^{\circ} \mathrm{C}\right)($ decreased from $29 \%$ to $9 \%, \mathrm{P}<0.001)$.

\section{Magnetic resonance imaging without sedation}

Sedation in preterm infants is associated with significant morbidity and mortality. Sedation has adverse effects on the cardiovascular and respiratory system in neonates. The most common adverse manifestation of sedation is respiratory depression, which is characterized by hypoxemia, apnoea, and hypoventilation. ${ }^{62}$

Stokowski $\mathrm{LA}^{62}$ described how infants are vulnerable to many of the potential hazards of MRIs, including projectile accidents, radiofrequency electromagnetic field effects, noise hazards, physiologic instability, and adverse effects of transport, positioning, handling, and sedation. He proposed the use of an MRI-compatible incubator. He opined that proper education of staff and meticulous attention to detail in preparing the infants for MR examinations are the keys to safety during neonatal MRI.

Haney et al. ${ }^{63}$ implemented a quality improvement intervention of using a vacuum immobilizer to during MRI to avoid the associated risks of sedation. MRI without the requirement of sedation was seen in $94 \%$ of the infants, and high-quality images were obtained in $97 \%$ of the attempts. Time away from the NICU was also reduced significantly with this intervention. Hence, the vacuum immobilizer is recommended as a quality improvement intervention for MRIs, which helps to avoid the risks associated with sedation.

Surana et al. ${ }^{64}$ demonstrated that educating medical and nursing staff and increasing awareness among them regarding accidental extubation can help decrease its occurrence by more than half.

Maria and Dasgupta highlighted the importance of family-centered care in the treatment of critically ill neonates. ${ }^{65}$ Family care and the provider care in the alliance have transformed the concept of neonatal care. Family-Centered care allows the care providers to improve the competencies of the parents or the caregivers in imparting care to their infants. This approach has been recently given importance as a quality improvement initiative to improve the neonatal care outcomes (Figure 2) (Figure 3). 


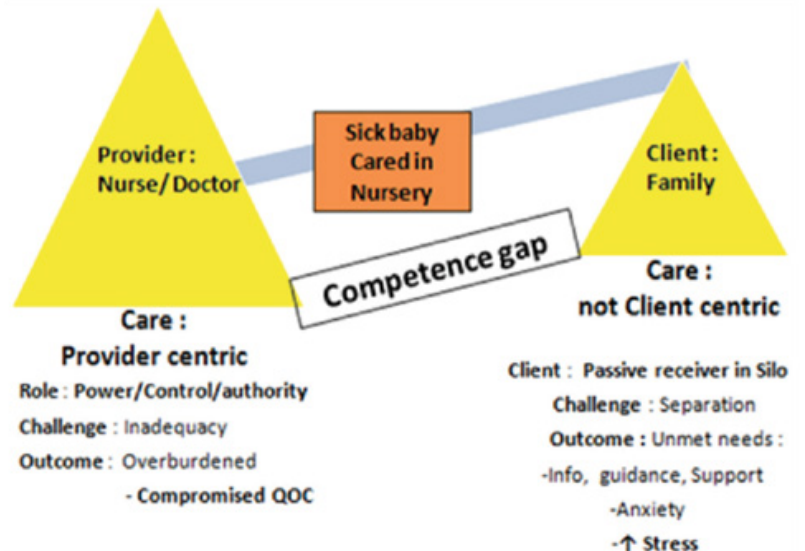

Figure 2 Conventional model for care of sick newborn; Adapted from "Familycentered care for sick newborns: A thumbnail view" $" 55$

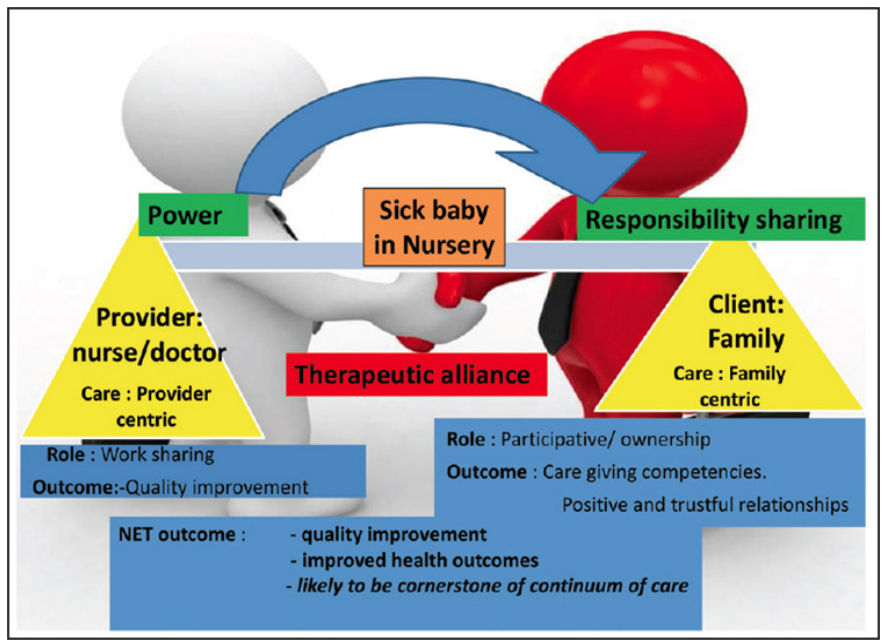

Figure 3 Family-centered care (FCC): A paradigm shift Adapted from "Family-centered care for sick newborns: A thumbnail view" 65

\section{Discussion}

Premature infants admitted to the NICU are more vulnerable to stressors than their mature counterparts. Exposure to light and noises, high risk of infections due to regular invasive procedures, pain due to invasive and surgical procedures, and less mother-infant interaction are some of the stress factors responsible for growth and developmental delays of preterm infants.

Quality improvement measures such as the use of music therapy or aquatic physical therapy can reduce the effects of environmental stressors like noises, and improve the sleep cycle of agitated and crying infants. Maintaining proper hand hygiene, maintenance and optimization of central venous catheters, and avoiding contamination while drawing the blood samples can reduce the infection risk, thereby reducing the utilization of antibiotics. Social interaction and oral feeding skills can be improved by increasing skin-to-skin care and mother-infant interaction. As premature infants have different nutrition requirements than their mature counterparts, it is important to provide them with fortified human or own mother's milk. This helps in providing the required nutrients which improve the growth of infants. Conditions such as lung injury and hypothermia can be prevented with minor precautions such as the use of prenatal corticosteroids and placing the infant in an occlusive bag to prevent heat loss, respectively (Tables 3) (Table 4).

These interventions are proven and have been shown to produce favorable outcomes in preterm infants in an NICU. Hence, future largescale studies need to be carried out to support the available evidence, and also to test additional new quality improvement interventions.

The major strength of this review is that it has synthesized not only the currently available evidence, but also a number of high-impact previous studies. This review has identified all the potential areas of improvement in the NICUs, along with the proven solutions or the interventions.

Neonatal morbidity and mortality has been a global public health challenge. Management of critically ill infants has become a major concern, as they are continuously exposed to various risk factors. Exposure to these stressors has a detrimental effect on the growth and neurodevelopment of critically ill preterm infants. As most of these causes are preventable, it is important to adopt various proven quality improvement initiatives to improve neonatal care outcomes. The proven quality improvement initiatives to improve the neonatal care outcomes include maintaining hand hygiene, maintenance and optimization of the central line, improving mother-infant interaction, reducing the risk of bronchopulmonary dysplasia and hypothermia, reducing the exposure of infants to various stressors, and implementing the family-centered care approach.

Table 3 Studies reporting outcomes of quality improvement initiatives for prevention of unplanned extubations

\begin{tabular}{|c|c|c|c|c|c|}
\hline SI. No & Study & Quality improvement initiative & $\begin{array}{l}\text { Unplanned } \\
\text { extubations per } \\
100 \text { days (pre } \\
\text { intervention) }\end{array}$ & $\begin{array}{l}\text { Unplanned } \\
\text { extubations per } \\
100 \text { days (post } \\
\text { intervention) }\end{array}$ & Conclusion of the study \\
\hline I & $\begin{array}{l}\text { Creeze KL et } \\
\text { al. }{ }^{54}\end{array}$ & $\begin{array}{l}\text { Providing awareness and education to } \\
\text { the NICU staffs, implementation of } \\
\text { standardised guidelineand and Quality } \\
\text { improvement initiative }\end{array}$ & 1.15 & 0.54 & $\begin{array}{l}\text { Considerable reduction } \\
\text { in the rate of unplanned } \\
\text { extubations. }\end{array}$ \\
\hline 2 & Surana et al. ${ }^{64}$ & $\begin{array}{l}\text { Workshops were conducted } \\
\text { to increase awareness among } \\
\text { NICU staff, regular assessment } \\
\text { of endotracheal tube fixation and } \\
\text { reporting of any adverse event }\end{array}$ & 2.98 & 1.14 & $\begin{array}{l}\text { Awareness and education } \\
\text { of NICU staff was shown } \\
\text { to play a significant role in } \\
\text { the reduction of unplanned } \\
\text { extubations }\end{array}$ \\
\hline
\end{tabular}


Table 4 Summary of studies

\begin{tabular}{|c|c|c|c|c|c|}
\hline SI. No & Study & Factor & QI intervention & Outcome & Similar studies \\
\hline I & Reavey et al. ${ }^{7}$ & $\begin{array}{l}\text { Pain assessment and } \\
\text { management }\end{array}$ & $\begin{array}{l}\text { Pain assessment and documentation } \\
\text { using a neonatal pain tool, N-PASS }\end{array}$ & $\begin{array}{l}\text { Considerable } \\
\text { improvement in pain } \\
\text { reduction strategies }\end{array}$ & - \\
\hline \multirow[t]{4}{*}{2} & Ting et al. ${ }^{9}$ & CLABSI prevention & 10 step regimen & $\begin{array}{l}\text { Considerable reduction in } \\
\text { rate of CLABSI }\end{array}$ & Bowen et al."' \\
\hline & & & & & Koeppel et al. ${ }^{12}$ \\
\hline & & & & & Zhou et al. ${ }^{14}$ \\
\hline & & & & & Byrd et al. ${ }^{15}$ \\
\hline 3 & Harris et al. ${ }^{16}$ & Sepsis prevention & $\begin{array}{l}\text { Neonatal nurses were designated to } \\
\text { draw the blood cultures instead of } \\
\text { phlebotomists }\end{array}$ & $\begin{array}{l}\text { Reduction in } \\
\text { contamination by } \\
\text { staphylococcal infections }\end{array}$ & Saiman ${ }^{18}$ \\
\hline 4 & Barbosa et al. ${ }^{34}$ & Hand hygiene & Use of alcohol based hand rub & $\begin{array}{l}\text { Reduction in the rate of } \\
\text { infections and usage of } \\
\text { antibiotics }\end{array}$ & Brown et al. ${ }^{35}$ \\
\hline \multirow[t]{2}{*}{5} & Chorna et al. ${ }^{39}$ & $\begin{array}{l}\text { Mother-infant } \\
\text { interaction }\end{array}$ & $\begin{array}{l}\text { pacifier activated music player with } \\
\text { mother's voice }\end{array}$ & $\begin{array}{l}\text { Improvement in the oral } \\
\text { feeding skills }\end{array}$ & Reynolds et al. ${ }^{40}$ \\
\hline & & & & & Dusing et al. ${ }^{41}$ \\
\hline \multirow[t]{4}{*}{6} & Luton et al. ${ }^{43}$ & Breast milk nutrition & $\begin{array}{l}\text { Expression of human milk, its storage } \\
\text { and fortification in this NICU were } \\
\text { carefully monitored }\end{array}$ & $\begin{array}{l}\text { Reduction in the human } \\
\text { milk errors }\end{array}$ & Meier et al. ${ }^{44}$ \\
\hline & & & & & Oza-Frank et al. ${ }^{45}$ \\
\hline & & & & & Liu et al., ${ }^{46}$ \\
\hline & & & & & $\begin{array}{l}\text { Boyd et al., }{ }^{47} \text { Cristofalo } \\
\text { et al. }{ }^{48}\end{array}$ \\
\hline 7 & Standley et al.. ${ }^{52}$ & Stress reduction & Music therapy & $\begin{array}{l}\text { Promotes neurological } \\
\text { maturation }\end{array}$ & 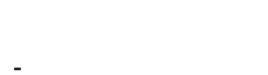 \\
\hline 8 & Vignochi et al. ${ }^{51}$ & Stress reduction & Aquatic physical therapy & $\begin{array}{l}\text { Improvement in sleep } \\
\text { cycle, reduced pain and } \\
\text { crying }\end{array}$ & - \\
\hline 9 & Creeze et al. ${ }^{54}$ & Unplanned extubation & $\begin{array}{l}\text { Providing awareness and education } \\
\text { to the NICU staffs, implementation } \\
\text { of standardised guidelineand and } \\
\text { Quality improvement initiative }\end{array}$ & $\begin{array}{l}\text { Reduction in the rate of } \\
\text { unplanned extubations }\end{array}$ & Surana et al. ${ }^{64}$ \\
\hline 10 & $\begin{array}{l}\text { Guimarães et } \\
\text { al. }^{56}\end{array}$ & $\begin{array}{l}\text { Bronchopulmonary } \\
\text { dysplasia }\end{array}$ & $\begin{array}{l}\text { Use of prenatal corticosteroids and } \\
\text { lowering the } \mathrm{FiO} 2\end{array}$ & $\begin{array}{l}\text { Decrease in the risk of } \\
\text { BPD }\end{array}$ & Schmidt et al. ${ }^{55}$ \\
\hline II & Godfrey et al. ${ }^{60}$ & Hypothermia & $\begin{array}{l}\text { Neonates to be placed in a bag } \\
\text { immediately after birth from down } \\
\text { the neck }\end{array}$ & Reduction in the heat loss & $\begin{array}{l}- \\
-\end{array}$ \\
\hline 12 & Haney et al. ${ }^{63}$ & MRI without sedation & Use of vacuum immobilizer & $\begin{array}{l}\text { Reduction in the risks of } \\
\text { hypothermia }\end{array}$ & \\
\hline
\end{tabular}

\section{Acknowledgments}

None.

\section{Conflict of interest}

The author declares no conflict of interest.

\section{References}

1. Qazi SA, Stoll BJ. Neonatal sepsis: a major global public health challenge. Pediatr Infect Dis J. 2009;28:S1-S2.

2. Adetola AO, Tongo OO, Orimadegun AE, et al. Neonatal mortality in an urban population in Ibadan, Nigeria. Pediatr Neonatol. 2011;52(5):243250.
3. Wilkinson DJ, Fitzsimons JJ, Dargaville PA, et al. Death in the neonatal intensive care unit: changing patterns of end of life care over two decades. Arch Dis Child Fetal Neonatal EdI. 2006;91(4):F268-F271.

4. Krishnan L. Pain relief in neonates. J Neonatal Surg. 2013;2(2):19.

5. Lago P, Boccuzzo G, Garetti E, et al. Pain management during invasive procedures at Italian NICUs: has anything changed in the last 5 years? $J$ Matern Fetal Neonatal Med. 2012;25:148-150.

6. Ozawa M, Yokoo K, Funaba Y, et al. Quality improvement collaborative program for neonatal pain management in Japan. Adv Neonatal Care. 2017;17(3):184-191.

7. Reavey DA, Haney BM, Atchison L, et al. Improving pain assessment in the NICU: a quality improvement project. Adv Neonatal Care. 2014;14(3):144-153. 
8. Wirtschafter DD, Pettit J, Kurtin P, et al. A statewide quality improvement collaborative to reduce neonatal central line-associated blood stream infections. Journal of Perinatology. 2010;30(3):170-181.

9. Ting JY, Goh VS, Osiovich H. Reduction of central line-associated bloodstream infection rates in a neonatal intensive care unit after implementation of a multidisciplinary evidence-based quality improvement collaborative: A four-year surveillance. Can J Infect Dis Med Microbiol. 2013;24(4):185-190.

10. Davis JW, Odd D, Jary S, et al. The impact of a sepsis quality improvement project on neurodisability rates in very low birthweight infants. Arch Dis Child Fetal Neonatal Ed. 2016;101:F562-F564.

11. Bowen JR, Callander I, Richards R, et al. Decreasing infection in neonatal intensive care units through quality improvement. Arch Dis Child Fetal Neonatal Ed. 2017;102:F51-F57.

12. Koeppel R, Uy C, Quan K. A 10 year review of central line associated blood stream infection prevention effortsin the neonatal intensive care unit: are improvements sustainable?. J Investig Med. 2016;64:252-253.

13. Kaplan HC, Lannon C, Walsh MC, et al. Ohio Perinatal Quality Collaborative. Ohio statewide quality-improvement collaborative to reduce late-onset sepsis in preterm infants. Pediatrics. 2011;127(3):427435 .

14. Zhou Q, Lee SK, Hu XJ, et al. Successful reduction in central lineassociated bloodstream infections in a Chinese neonatal intensive care unit. Am J Infect Control. 2015;43(3):275-279.

15. Byrd P, Porter M, Petersen M. Nurse-Driven Quality Improvement Project to Reduce CLABSI Rates in a Level III Community NICU. Am J Infect Control. 2011;39(5):E44-E45.

16. Harris J, Stone S, Stromquist C, et al. Improving the quality of care by reducing contamination when drawing blood cultures in the neonatal intensive care unit. American Journal of Infection Control. 2012;40(5):e145-e146.

17. Bizzarro MJ1, Sabo B, Noonan M, et al. Central Venous Catheter Initiative Committee. A quality improvement initiative to reduce central line-associated bloodstream infections in a neonatal intensive care unit. Infect Control Hosp Epidemiol. 2010;31(3):241-248.

18. Saiman L. Strategies for prevention of nosocomial sepsis in the neonatal intensive care unit. Curr opin pediatr. 2006;18(2):101-106.

19. Pammi M, Abrams SA. Oral lactoferrin for the prevention of sepsis and necrotizing enterocolitis in preterm infants. Cochrane Database Syst Rev. 2015;(2):CD007137.

20. Hsueh W, Caplan MS, Qu XW, et al. Neonatal necrotizing enterocolitis: clinical considerations and pathogenetic concepts. Pediatr Dev Pathol. 2003;6(1):6-23.

21. Johnson TJ, Patel AL, Bigger HR, et al. Cost savings of human milk as a strategy to reduce the incidence of necrotizing enterocolitis in very low birth weight infants. Neonatology. 2015;107(4):271-276.

22. Horbar JD, Carpenter JH, Badger GJ, et al. Mortality and neonatal morbidity among infants 501 to 1500 grams from 2000 to 2009 Pediatrics. 2012;129(6):1019-1026.

23. Fitzgibbons SC, Ching Y, Yu D, et al. Mortality of necrotizing enterocolitis expressed by birth weight categories. J Pediatr Surg. 2009;44(6):1072-1075.

24. Sharma R, Hudak ML. A clinical perspective of necrotizing enterocolitis: past, present, and future. Clin Perinatol. 2013;40(1):27-51.

25. Rabe H, Diaz-Rossello JL, Duley L, et al. Effect of timing of umbilica cord clamping and other strategies to influence placental transfusion at preterm birth on maternal and infant outcomes. Cochrane Database Syst Rev. 2012;8:CD003248
26. Garg BD, Kabra NS, Bansal A. Role of delayed cord clamping in prevention of necrotizing enterocolitis in preterm neonates: a systematic review. J MaternFetal Neonatal Med. 2017;32(1):1-9.

27. Patel S, Clark EA, Rodriguez CE, et al. Effect of umbilical cord milking on morbidity and survival in extremely low gestational age neonates. $\mathrm{Am}$ J ObstetGynecol. 2014;211(5):519.e1-e7.

28. Talavera MM, Bixler G, Cozzi C, et al. Quality improvement initiative to reduce the necrotizing enterocolitis rate in premature infants. Pediatrics. 2016;137(5):e20151119.

29. Alshaikh B, Kostecky L, Blachly N, et al. Effect of a Quality improvement project to use exclusive Mother's own milk on rate of necrotizing enterocolitis in preterm infants. Breastfeed Med. 2015;10(7):355-361

30. Aceti A, Gori D, Barone G, et al. Probiotics for prevention of necrotizing enterocolitis in preterm infants: systematic review and meta-analysis. Ital J Pediatr. 2015;41:89.

31. AlFaleh K, Anabrees J. Probiotics for prevention of necrotizing enterocolitis in preterm infants. Cochrane Database Syst Rev. 2014;4:CD005496.

32. Helder OK, Weggelaar AM, Waarsenburg DC, et al. Computer screen saver hand hygiene information curbs a negative trend in hand hygiene behavior. Am J Infect Control. 2012;40(10):951-954

33. Lam BC, Lee J, Lau YL. Hand hygiene practices in a neonatal intensive care unit: a multimodal intervention and impact on nosocomial infection. Pediatrics. 2004;114(5):e565-571.

34. Barbosa LR, Rego MAS, Santos AM, et al. Hand hygiene compliance at neonate intensive care unit in a Brazilian hospital. BMC Proceedings 2011;5(Suppl 6):128.

35. Brown SM, Lubimova AV, Zueva LP, et al. Use of an alcohol-based handrub and quality improvement interventions to improve hand hygiene in a Russian neonatal intensive care unit. Infect Control Hosp Epidemiol. 2003;24(3):191.

36. Ofek Shlomai N, Rao S, Patole S. Efficacy of interventions to improve hand hygiene compliance in neonatal units: a systematic review and meta-analysis. Eur J Clin Microbiol Infect Dis. 2015;34(5):887-897.

37. Forcada-Guex M, Pierrehumbert B, Borghini A, Moessinger A, MullerNix C. Early dyadic patterns of mother-infant interactions and outcomes of prematurity at 18 months. Pediatrics. 2006;118(1):e107-e114.

38. Smith KE, Landry SH, Swank PR. The influence of early patterns of positive parenting on children's preschool outcomes. Early Edu Develop. 2000;11:147-169.

39. Chorna OD, Slaughter JC, Wang L, et al. A pacifier-activated music player with mother's voice improves oral feeding in preterm infants. Pediatrics. 2014;133(3):462-468.

40. Reynolds LC, Duncan MM, Smith GC, et al. Parental presence and holding in the neonatal intensive care unit and associations with early neurobehavior. J Perinat. 2013;33(8):636-641.

41. Dusing S, Brown L, Thacker L, et al. Supporting mother-infant interaction in the NICU may enhance oral motor skills, weight gain, and feeding volume: a pilot study. Dev Med Child Neurol. 2016;58:13-14

42. Underwood MA. Human milk for the premature infant. Pediatr Clin North Am. 2013;60(1):189-207.

43. Luton A, Bondurant PG, Campbell A, et al. Got (the Right) Milk? How a Blended Quality Improvement Approach Catalyzed Change. Adv Neonatal Care. 2015;15(5):345-353.

44. Meier PP, Engstrom JL, Patel AL, et al. Improving the use of human milk during and after the NICU stay. Clin Perinatol. 2010;37(1):217-245. 
45. Oza-Frank R, Kachoria R, Dail J, et al. A Quality Improvement Project to Decrease Human Milk Errors in the NICU. Pediatrics. 2017;139(2):e20154451.

46. Liu F, Han SP, Yu ZB, et al. Effect of breastfeeding quality improvement on breastfeeding rate in very low birth weight and extremely low birth weight infants. Zhongguo Dang Dai Er Ke Za Zhi. 2016;18:937.

47. Boyd CA, Quigley MA, Brocklehurst P. Donor breast milk versus infant formula for preterm infants: systematic review and meta-analysis. Arch Dis Child Fetal Neonatal Ed. 2007;92(3):F169-175.

48. Cristofalo EA, Schanler RJ, Blanco CL, et al. Randomized trial of exclusive human milk versus preterm formula diets in extremely premature infants. The Journal of pediatrics. 2013;163(6):1592-1595

49. Smith GC, Gutovich J, Smyser C, et al. Neonatal intensive care unit stress is associated with brain development in preterm infants. Ann Neurol. 2011;70(4):541-549.

50. Floyd AMD. An NICU infant stress reduction QI team: applying research findings to clinical care. Jt Comm J Qual Improv 1997;23(2):93-101.

51. Vignochi C, Teixeira PP, Nader SS. Effect of aquatic physical therapy on pain and state of sleep and wakefulness among stable preterm newborns in neonatal intensive care units. Braz J Phys Ther. 2010;14:214-220.

52. Standley JM. Shortening neonatal intensive care unit stay and improving medical outcomes for premature infants using evidence-based music therapy protocols. J Investig Med. 2015;63:422-422.

53. Veldman A, Trautschold T, WEIss KATJA, et al. Characteristics and outcome of unplanned extubation in ventilated preterm and term newborns on a neonatal intensive care unit. Pediatr Anesth 2006;16(9):968-973.

54. Crezeé KL, DiGeronimo RJ, Rigby MJ et al. Reducing Unplanned Extubations in the NICU Following Implementation of a Standardized Approach. Respiratory Care. 2017;62(8):1030-1035.

55. Schmidt B, Roberts R, Millar D, et al. Evidence-based neonatal drug therapy for prevention of bronchopulmonary dysplasia in very-lowbirth-weight infants. Neonatology. 2008;93(4):284-287.
56. Guimarães $H$, Rocha $G$, Vasconcellos $G$, et al. Bronchopulmonary dysplasia: Clinical practices in five Portuguese neonatal intensive care units. Rev Port Pneumol. 2010;16(2):273-286.

57. Picarillo AP, Carlo W. Using Quality Improvement Tools to Reduce Chronic Lung Disease. Clin Perinatol. 2017;44(3):701-712.

58. Payne NR, LaCorte M, Sun S, et al. Evaluation and development of potentially better practices to reduce bronchopulmonary dysplasia in very low birth weight infants. Pediatrics. 2006;118 Suppl 2:S65-72.

59. Levesque BM, Kalish LA, LaPierre J, et al. Impact of implementing 5 potentially better respiratory practices on neonatal outcomes and costs. Pediatrics. 2011;128(1):e218-226.

60. Godfrey K, Nativio DG, Bender CV, et al. Occlusive bags to prevent hypothermia in premature infants: a quality improvement initiative. $A d v$ Neonat Care. 2013;13(5):311-316.

61. Harer MW, Vergales B, Cady T, et al. Implementation of a multidisciplinary guideline improves preterm infant admission temperatures. J Perinatol. 2017;37(11):1242-1247.

62. Stokowski LA. Ensuring safety for infants undergoing magnetic resonance imaging. Adv Neonatal Care. 2005;5(1):14-27.

63. Haney B, Reavey D, Atchison L, et al. Magnetic resonance imaging studies without sedation in the neonatal intensive care unit: safe and efficient. J Perinat Neonatal Nurs. 2010;24(3):256-266.

64. Surana P, Gowda S. G110 (P) Preventing accidental extubations in NICU-a quality improvement project. Archives of Disease in Childhood. 2014;99(Suppl 1):A46-A47.

65. Maria A, Dasgupta R. Family-centered care for sick newborns: A thumbnail view. Indian J Community Med. 2016;41:11

66. Ellsbury DL, Clark RH, Ursprung R, et al. A multifaceted approach to improving outcomes in the NICU: The Pediatrix 100000 Babies Campaign. Pediatrics. 2016;137(4):e20150389. 